\title{
AGROMETEOROLOGIA
}

\section{COMPARAÇÃO MICROCLIMÁTICA DE AMBIENTE DE VÁRZEA E DE POSTO METEOROLÓGICO(1)}

\author{
ANDREW PATRICK CIARELLI BRUNINI ${ }^{(2)}$; MARIO JOSÉ PEDRO JÚNIOR ${ }^{(3)}$; PAULO BOLLER GALLO ${ }^{(4)}$
}

\begin{abstract}
RESUMO
Foi realizado um estudo visando comparar os ambientes de várzea sistematizada e de posto meteorológico, no município de Mococa (SP), por meio de medições de temperatura e umidade relativa do ar, radiação solar global e velocidade do vento. No ambiente de várzea, foi medido também o saldo de radiação. A comparação de médias foi feita por análise de dados pareados, de outubro a março (representando as condições de primavera/verão) e de abril a julho (outono e inverno). A evapotranspiração na escala diária foi estimada pelo método de Penman-Monteith, adotado como padrão pela FAO. No período outono-inverno $(\mathrm{O}-\mathrm{I})$, observou-se que, para a temperatura máxima do ar, a diferença média entre os ambientes foi de $0,1{ }^{\circ} \mathrm{C}$; para a temperatura mínima do ar, a várzea apresentou média inferior de 3,4 ${ }^{\circ} \mathrm{C}$, enquanto no período de primavera-verão as temperaturas máximas, na várzea, foram, em média, 0,9 ${ }^{\circ} \mathrm{C}$ mais elevadas que no posto meteorológico. Os valores de evapotranspiração, no período de primavera/verão, os dois ambientes analisados foram muito semelhantes. A evapotranspiração em ambos os ambientes variou entre 1,0 e 7,8 mm por dia com valores máximos ocorrendo no período outubro/ novembro. Durante o outono/inverno as estimativas feitas para o posto meteorológico foram superiores em 1,6 mm por dia às da várzea. No período de outono-inverno foram mais acentuadas as diferenças entre várzea e posto meteorológico.
\end{abstract}

Palavras-chave: microclima, várzea, temperatura, umidade relativa, evapotranspiração.

\section{ABSTRACT \\ MICROCLIMATIC COMPARISON OF THE ENVIRONMENT OF WEATHER STATION AND FLOODPLAINS}

A study was conducted to compare the systematic flood plain environment and that of a Weather Station. The survey was conducted in the Mococa county, São Paulo State, Brazil. The measurements of the microclimatic parameters at the weather station and floodplain environment were made by means of the automated weather station (SCI) determining: temperature and relative humidity of the air, and global solar radiation. In the floodplain environment the net radiation was also measured. The average values were compared by paired comparison analysis, for the months from October to March (representing spring and summer conditions) and the months from April to July (representing autumn and winter

$\left({ }^{1}\right)$ Recebido para publicação em 11 de julho de 2003 e aceito em 26 de abril de 2004.

$\left({ }^{2}\right)$ Curso de Pós Graduação em Agricultura Tropical e Subtropical, Instituto Agronômico (IAC), Caixa Postal 28 , 13001-970 Campinas (SP).

$\left(^{3}\right)$ Instituto Agronômico (IAC/APTA). Bolsista do CNPq. E-mail: mpedro@iac.sp.gov.br

$\left({ }^{4}\right)$ Polo Regional de Desenvolvimento Tecnológico do Nordeste Paulista (DDD/APTA), Caixa Postal 58, 13730-970 Mococa (SP). 
conditions). The evapotranspiration in the daily scale was estimated by the Penman-Monteith method adopted by FAO. During the autumn-winter (O-I) period, in the floodplain, it was observed that the average maximum air temperature were $0.1^{\circ} \mathrm{C}$ and the minimum air temperature was found to be $3.4^{\circ} \mathrm{C}$ lower than the weather station environment. During autumn-winter period the maximum temperatures, at the floodplain, were $0,9{ }^{\circ} \mathrm{C}$ higher than the standard weather conditions. Considering the evapotranspiration in the spring/summer period, the values in the two conditions analyzed (station vs. floodplain) were very similar. Evapotranspiration in both environments varied between 1.0 and $7.8 \mathrm{~mm} /$ day with maximum values occurring during the October/November period. On the other hand, the estimates made during the autumn/winter period for the weather station were higher, than those made for the floodplain. In the autumn/winter period the evapotranspiration estimated for the station were mostly superior ( $1.6 \mathrm{~mm} /$ day) to those of the floodplain. During the autumn/winter period the differences between the environment of flood plains and weather station were higher showing that for the floodplains the microclimatic parameters are more extreme than for the weather station.

Key-words: microclimate, temperature, relative humidity, evapotranspiration.

\section{INTRODUÇÃO}

As várzeas são extensões de terra localizadas à margem de rios ou lagos, cuja topografia permite a exploração de culturas adaptadas a esse ambiente e apresentam grande potencial de exploração no Estado de São Paulo. Apesar da importância em conhecer o comportamento da temperatura e da umidade relativa nesse ambiente, poucos trabalhos existem na quantificação das condições de várzea e suas relações com as características macroclimáticas determinadas em condição de Posto Meteorológico.

Yoshino (1975) descreve que em condições de microclima como várzeas, vales e bases de montanha a temperatura do ar é mínima no local onde a altitude é menor, tanto pelo resfriamento da superfície como pelo acúmulo do ar frio. Esse mesmo autor também ressalta que a temperatura máxima do ar apresenta menores diferenças, por ser essa função da taxa de resfriamento do ar e da exposição de vertente.

CAMARgo (1972) afirma que os terrenos de baixada para onde converge o ar frio das adjacências, tornando-se cada vez mais frios e úmidos, ficam mais sujeitos à ocorrência de temperaturas mínimas mais baixas. Essa redução mais acentuada de temperatura propicia um aumento da umidade relativa do ar, induzindo, muitas vezes, à ocorrência de orvalho e neblina.

Os trabalhos existentes na literatura visam quantificar as variações da temperatura e umidade do ar em diferentes ambientes, porém poucos estão diretamente relacionados ao ambiente de várzea.

Embora o clima seja determinado pelos parâmetros ou fatores climáticos, grandes extensões de água ou florestas têm impactos locais pela redução, principalmente, na amplitude térmica, embora GEIGER (1950) afirme que a caracterização isolada da influência de uma floresta sobre o clima seja dificultada pelos fatores macroclimáticos e a própria variabilidade sazonal e temporal dos elementos meteorológicos.

A evapotranspiração é outro fator importante a ser avaliado, principalmente, devido às características topográficas e de umidade do solo que ocorrem em condições de várzea.

Existem inúmeras fórmulas de estimativa da evapotranspiração (PereIRA et al. 1997), e o uso de cada uma delas está condicionado à disponibilidade ou existência dos parâmetros necessários à sua aplicação. Dentre essas destaca-se a de Penman (Penman, 1948), principalmente para estimativas diárias.

Berlato e Molion (1981), analisando a fórmula de Penman para estimativa da evaporação, verificaram que sua expressão fora derivada para a superfície livre de água e, no caso de se analisar a evapotranspiração, os fatores de solo e planta devem ser incluídos. Posteriormente, objetivando estimativas de evapotranspiração para culturas agrícolas, a fórmula de Penman foi adaptada, tendo sido incluídos parâmetros de resistência da cultura e do ar ao transporte de vapor d'água .

Автеw (1996) comparou diferentes métodos para estimativa da evapotranspiração em regiões de terras úmidas, nos Everglades da Flórida, e observou que a fórmula de Penman-Monteith apresentou as menores diferenças em comparação aos valores medidos.

Wessel e Rouse (1994), ao modelar a evaporação de Tundra, comparando diferentes métodos e uma versão modificada do método de Penman-Monteith ,verificam que este último obteve maior potencial de uso nessas condições.

Mao et al (2002) estudaram as taxas de evapotranspiração estimadas e medidas em diferentes ambientes de áreas inundáveis na Flórida (USA), utilizando o método de Penman-Monteith. Os resultados 
mostraram que as estimativas da evapotranspiração, em base mensal, foram muito próximas aos valores medidos.

O rápido avanço das técnicas de medidas dos parâmetros meteorológicos com o uso de Estações Meteorológicas Automáticas (Hubbard e SivaKumar, 2001) deve ser considerado na utilização dos diferentes métodos de estimativa da evapotranspiração, em especial para uso da fórmula de Penman-Monteith.

Com base no trabalho de Allen et al. (1989), a FAO (AlLEN et al.,1998) recomendou a adoção do método de Penman-Monteith como padrão para a estimativa da evapotranspiração de referência e vários testes têm sido realizados nas condições brasileiras para a escala diária.

Pereira et al. (2002b) comprovaram o uso adequado dos dados de estações meteorológicas automáticas (EMA) para estimativa da evapotranspiração de referência diária, com base no boletim FAO-56 (AlLEN et al., 1998), comparando com os resultados de estações convencionais e de medidas lisimétricas de evapotranspiração.

As várzeas devido às áreas características peculiares de topografia e alta disponibilidade de umidade do solo durante todo o ano necessitam de estudos mais detalhados de medição de temperatura e umidade de ar e de estimativa de evapotranspiração. Portanto, foi desenvolvido este experimento visando caracterizar o ambiente de várzea e comparar com ambiente de posto meteorológico.

\section{MATERIAL E MÉTODOS}

O experimento foi desenvolvido em área experimental do Pólo Regional de Desenvolvimento Tecnológico dos Agronegócios do Nordeste Paulista (DDD/APTA), localizado no município de Mococa (latitude: $21^{\circ} 28^{\prime}$ Sul; longitude: $47^{\circ} 01^{\prime}$ Oeste e altitude: $665 \mathrm{~m}$ ).

O clima da região, de acordo com a classificação de Köppen, é Aw, com verão úmido e inverno seco. A temperatura média anual é de $22,4{ }^{\circ} \mathrm{C}$, e o total médio anual de precipitação pluvial é de $1.514 \mathrm{~mm}$.

Os ambientes monitorados foram de posto meteorológico e de várzea sistematizada. As medições dos parâmetros microclimáticos em ambiente de posto meteorológico com grama batatais, e área útil $30 \mathrm{x}$ $30 \mathrm{~m}$ foram feitas por meio de Estação Meteorológica Automática, modelo Campbell Scientific, e os sensores utilizados foram: a) temperatura do ar/umidade relativa do ar -modelo HMP45C; b) anemômetro Met-One, modelo 014A; c) radiação solar - radiômetro - Kipp e Zonen - modelo SP Lite.
A estação meteorológica automática possuía um sistema de coleta e armazenamento dos registros dos sinais dos sensores (Campbell Scientific, modelo CR 10X).

A várzea sistematizada compreende uma área de 15 ha sendo grande parte cultivada com arroz inundado durante o verão e aveia e trigo no inverno. Aproximadamente $2 / 3$ foi deixada em pousio, local onde se realizou o monitoramento dos parâmetros em escala microclimática. Confronta-se ao Norte com o rio das Onças e sua vegetação ciliar, e ao Sudoeste com uma pequena elevação que configura a área de várzea.

A vegetação dominante constituía-se de plantas daninhas, composta de tiriricão (Echinochloa crusgalli) (80\%), capim arroz (Cyperus esculentus) (15\%) e outras de menor ocorrência (5\%). Dessa maneira, a vegetação se assemelhava à de grama do Posto Meteorológico, sendo a altura da cobertura vegetal entre 15 e $20 \mathrm{~cm}$ na maioria do período de realização do experimento. No ambiente de várzea foi medido, além dos parâmetros relacionados para ambiente de posto meteorológico, o saldo de radiação por meio de saldo radiômetro (Campbell Scientific, Inc - modelo Q-7).

Para caracterizar a variação dos valores diários da temperatura do ar máxima e mínima, radiação solar global, umidade relativa do ar em ambiente de várzea e de posto meteorológico e saldo de radiação apenas na várzea, foram analisados os valores extremos e/ou médias diárias dos valores obtidos nas estações meteorológicas automáticas. As medições foram feitas no período de outubro de 2001 a julho de 2002 agrupando-se outubro a março, representando as condições de primavera/verão, e abril a julho, representando outono/inverno.

Os valores diários dos diferentes parâmetros foram submetidos à análise de variância de dados emparelhados ou pareados (SOKAL e ROHLF, 1969) para comparação entre os diferentes ambientes analisados e verificou-se a significância pelo teste $F$.

A evapotranspiração foi estimada pelo método de Penman, adaptado por Allen et al. (1989) em escala diária. Atualmente, é o método-padrão adotado pela FAO (ALLEN et al., 1998), sendo ETP (mm.d $\mathrm{d}^{-1}$ ) dada pela seguinte fórmula, conforme descrito em PEREIRA et al.(2002a):

$$
E T P=\frac{0,408 \mathrm{~s}(\mathrm{Rn}-\mathrm{G})+\frac{\gamma 900 \mathrm{U}_{2}\left(e_{s}-e_{a}\right)}{T+273}}{s+\gamma\left(1+0,34 U_{2}\right)}
$$


sendo: Rn - o saldo de radiação total diária $\left(\mathrm{MJ} \cdot \mathrm{m}^{-2} \cdot \mathrm{d}^{-1}\right) ; \mathrm{G}$ - o fluxo de calor no solo $\left(\mathrm{MJ} \mathrm{m}^{-2} \cdot \mathrm{d}^{-1}\right)$; $\mathrm{g}=0,063 \mathrm{kPa}{ }^{\circ} \mathrm{C}^{-1}$ - a constante psicrométrica; $\mathrm{T}$ - a temperatura média do ar $\left({ }^{\circ} \mathrm{C}\right) ; \mathrm{U}_{2}$ - a velocidade do vento a $2 \mathrm{~m}$ de altura $\left(\mathrm{m} \cdot \mathrm{s}^{-1}\right) ; \mathrm{e}_{\mathrm{s}}$ - a pressão de saturação de vapor $(\mathrm{kPa}) ; \mathrm{e}_{\mathrm{a}}$ - a pressão parcial de vapor $(\mathrm{kPa})$; e $s$ - a declividade da curva de pressão de vapor na temperatura do ar, em $\mathrm{kPa}^{\circ} \mathrm{C}^{-1}$, dado por:

$$
\begin{aligned}
& \mathrm{s}=(4098 \cdot \mathrm{es}) /(\mathrm{T}+237,3)^{2} \\
& \mathrm{es}=\left(\mathrm{es}_{\mathrm{Tmax}}+\mathrm{es}_{\mathrm{Tmin}}\right) / 2 \\
& \mathrm{es}_{\text {Tmax }}=0,6108 \cdot \mathrm{e}^{[(17,27 . T \operatorname{Tmax}) /(237,3+\mathrm{Tmax})]} \\
& \mathrm{es}_{\text {Tmin }}=0,6108 \cdot \mathrm{e}^{[(17,27 \mathrm{Tmin}) /(237,3+\mathrm{Tmin})]} \\
& \mathrm{ea}=(\mathrm{URmed} \cdot \mathrm{es}) / 100 \\
& \mathrm{URmed}=(\mathrm{URmax}+\mathrm{URmin}) / 2 \\
& \mathrm{~T}=(\text { Tmax }+ \text { Tmin }) / 2
\end{aligned}
$$

sendo: Tmax - a temperatura máxima do ar $\left({ }^{\circ} \mathrm{C}\right)$; Tmin - a temperatura mínima do ar $\left({ }^{\circ} \mathrm{C}\right)$; Urmax - a umidade relativa máxima do ar (\%); Urmin - a umidade relativa mínima do ar (\%).

Para o ambiente de posto meteorológico o saldo de radiação foi estimado em função da radiação solar global como sugerido por PEREIRA (1998):

$$
\begin{aligned}
& \mathrm{Rn}=0,574 \text { Rs } \\
& \text { Rs - a radiação solar global }\left(\mathrm{MJ} \cdot \mathrm{m}^{-2} \cdot \mathrm{d}^{-1}\right)
\end{aligned}
$$

\section{RESULTADOS E DISCUSSÃO}

A caracterização do microclima, as análises e a comparação entre os ambientes de várzea e os de posto meteorológico foram divididas em virtude das estações do ano, e das características do estudo, em dois segmentos: primavera/verão e outono/inverno.

\subsection{Temperatura do ar}

A variação dos valores de temperatura do ar máxima e mínima diários referentes ao período primavera/verão é mostrada na Figura 1. Esse período é caracterizado por um aumento de temperatura do ar do início da primavera até março, e com uma característica de precipitação pluviométrica com índices menores, baixos na primavera e maiores durante o verão.

Os valores máximos e mínimos médios foram, respectivamente, de $31,3{ }^{\circ} \mathrm{C}$ e $18,9^{\circ} \mathrm{C}$ para a várzea e de $30,4{ }^{\circ} \mathrm{C}$ e $19,4{ }^{\circ} \mathrm{C}$, para as condições do posto meteorológico, mostrando-se as temperaturas máximas superiores, em $0,9{ }^{\circ} \mathrm{C}$, na várzea em relação ao posto meteorológico, enquanto as mínimas foram inferiores, em média $0,5^{\circ} \mathrm{C}$, na condição de várzea.

A variação dos valores diários das temperaturas máximas e mínimas nos ambientes durante o período de outono/inverno é apresentada na Figura 2. Deve-se ressaltar que o período outono/inverno caracteriza-se por uma diminuição constante da temperatura do ar, de abril a julho, assim como da precipitação pluvial.

Observa-se que com relação à temperatura máxima do ar durante o período de outono/inverno as diferenças não são marcantes entre os ambientes (Várzea-Posto), com diferença média de $0,2{ }^{\circ} \mathrm{C}$. Em relação à temperatura mínima do ar, porém, a várzea foi em média $3,2{ }^{\circ} \mathrm{C}$ inferior à do posto, no período outono/inverno, com valores extremos até de $6,4{ }^{\circ} \mathrm{C}$ inferior à do posto (15/maio). Esse fato pode ser explicado pelo maior acúmulo de ar frio na baixada (várzea), em função da sua topografia.

Esses resultados corroboram as afirmações de Yoshino (1975), ao afirmar que comparando-se as características térmicas de clima local (microclima) em relação às variações macroclimáticas, as maiores diferenças são observadas na temperatura mínima do ar devido ao acúmulo de ar frio.

A amplitude térmica nas condições de várzea foi maior que no posto meteorológico. Na várzea, no período primavera/verão a amplitude térmica média foi $12,3{ }^{\circ} \mathrm{C}$, enquanto no posto a amplitude térmica média foi $11,0^{\circ} \mathrm{C}$. Já no período outono/inverno, a amplitude térmica média da várzea foi $17,7^{\circ} \mathrm{C}$, enquanto no posto, $14,2{ }^{\circ} \mathrm{C}$, devido às condições topoclimáticas, que permitem maior acúmulo de ar frio nas condições de várzea, induzindo à menor temperatura noturna e, conseqüentemente, maior amplitude térmica que no posto meteorológico. Deve-se salientar também que essas condições se acentuam a partir de maio, quando as condições locais para acúmulo de ar frio são favorecidas.

\subsection{Umidade relativa do ar}

A comparação dos valores extremos da umidade relativa do ar é apresentada na figura 3 para o período primavera/verão e na figura 4 para outono/ inverno.

Observa-se que ocorreram pequenas diferenças nos valores máximos da umidade relativa do ar; na várzea, notaram-se valores superiores ao do posto meteorológico, provavelmente em vista da maior umidade do solo em condições de várzea. Com relação aos valores da umidade relativa mínima do ar verificou-se que as diferenças foram muito menores. 


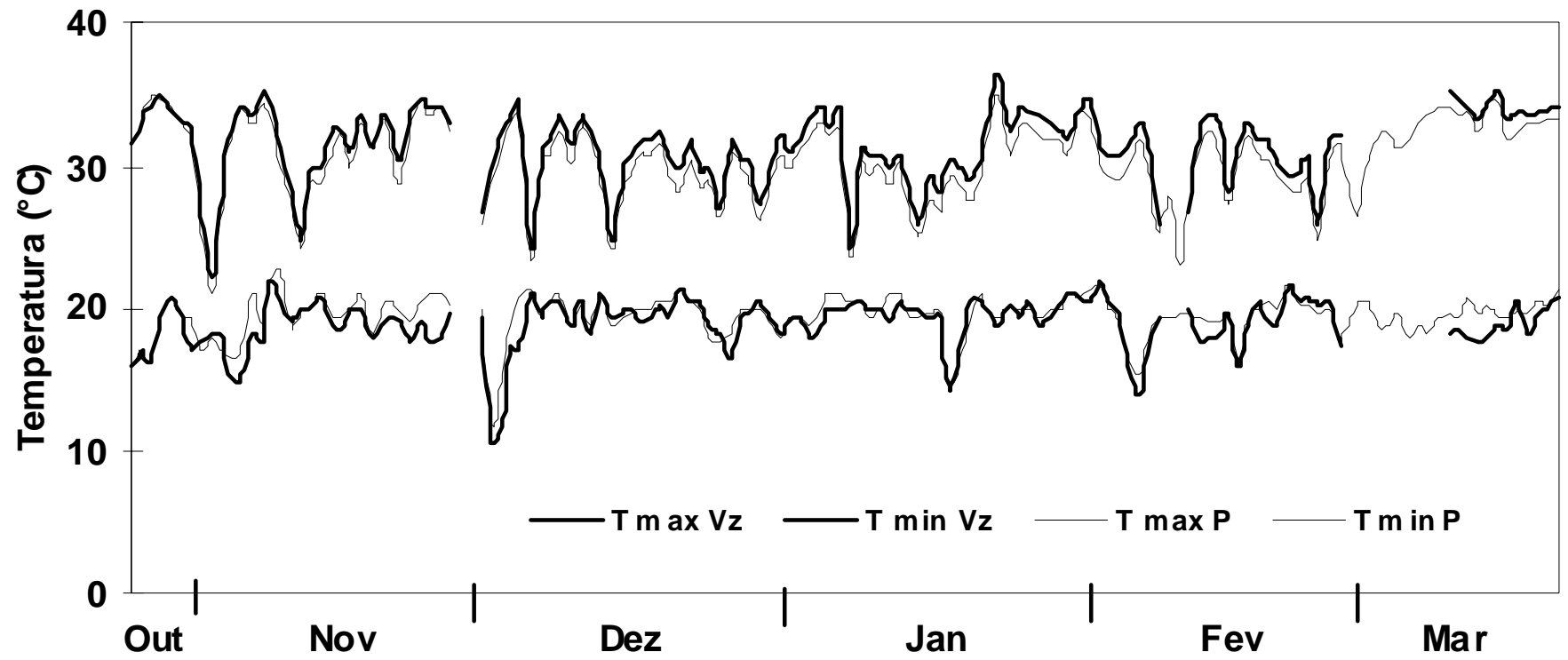

Figura 1. Temperatura máxima (Tmax) e mínima (Tmin) do ar para as condições de várzea (VZ) e de posto meteorológico (P), observadas durante o período de outubro/2001 a março/2002, em Mococa (SP).

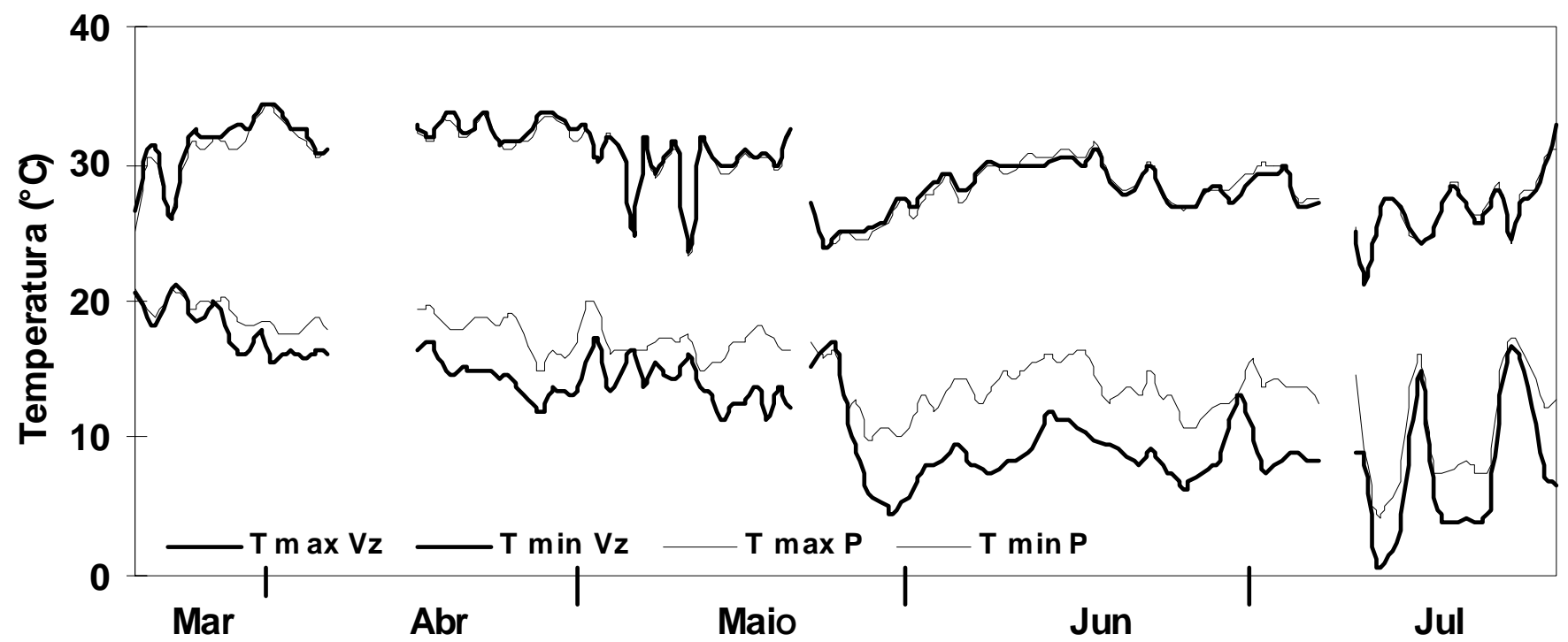

Figura 2. Temperatura máxima (Tmax) e mínima (Tmin) do ar para as condições de várzea (VZ) e de posto meteorológico (P), observadas durante o período de março/2002 a julho/2002, em Mococa (SP). 


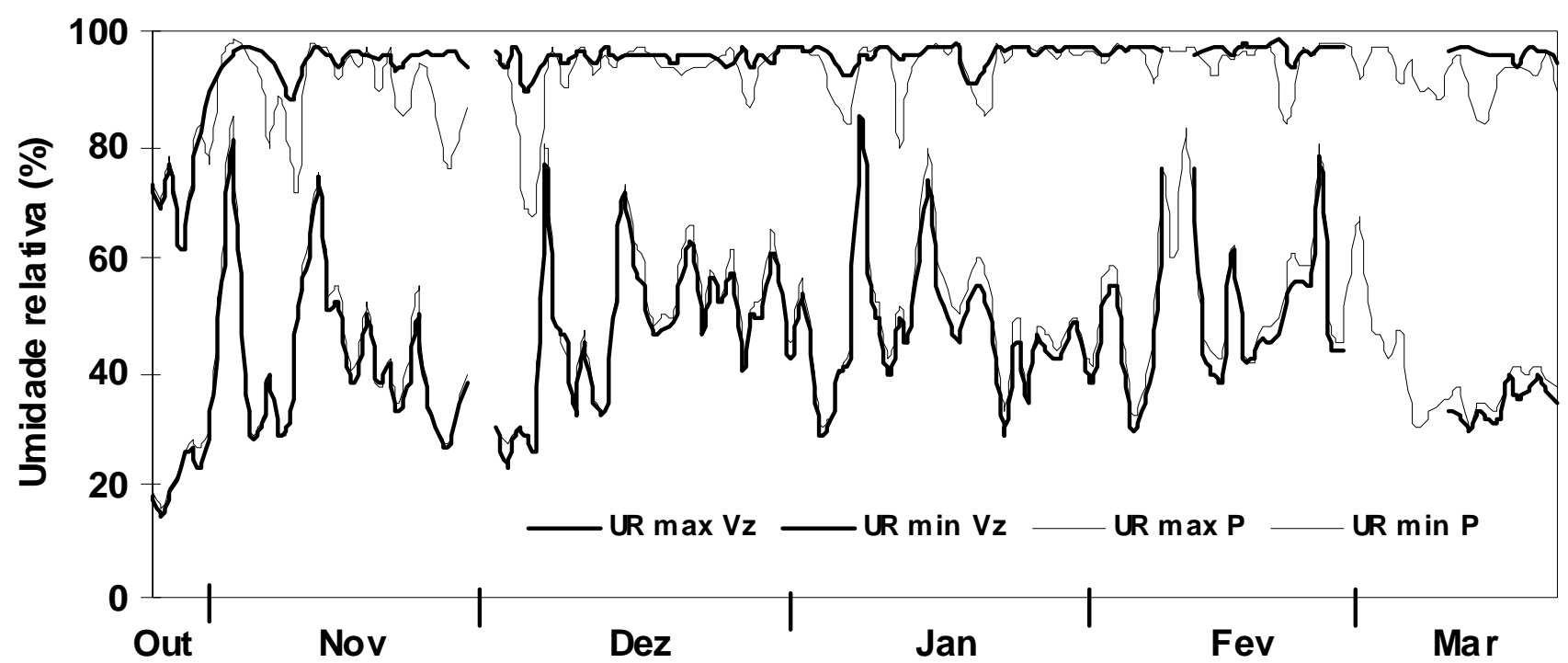

Figura 3. Umidade relativa máxima (URmax) e mínima (URmin) do ar para as condições de várzea (VZ) e de posto meteorológico (P), observadas durante o período de outubro/2001 a março/2002, em Mococa (SP).

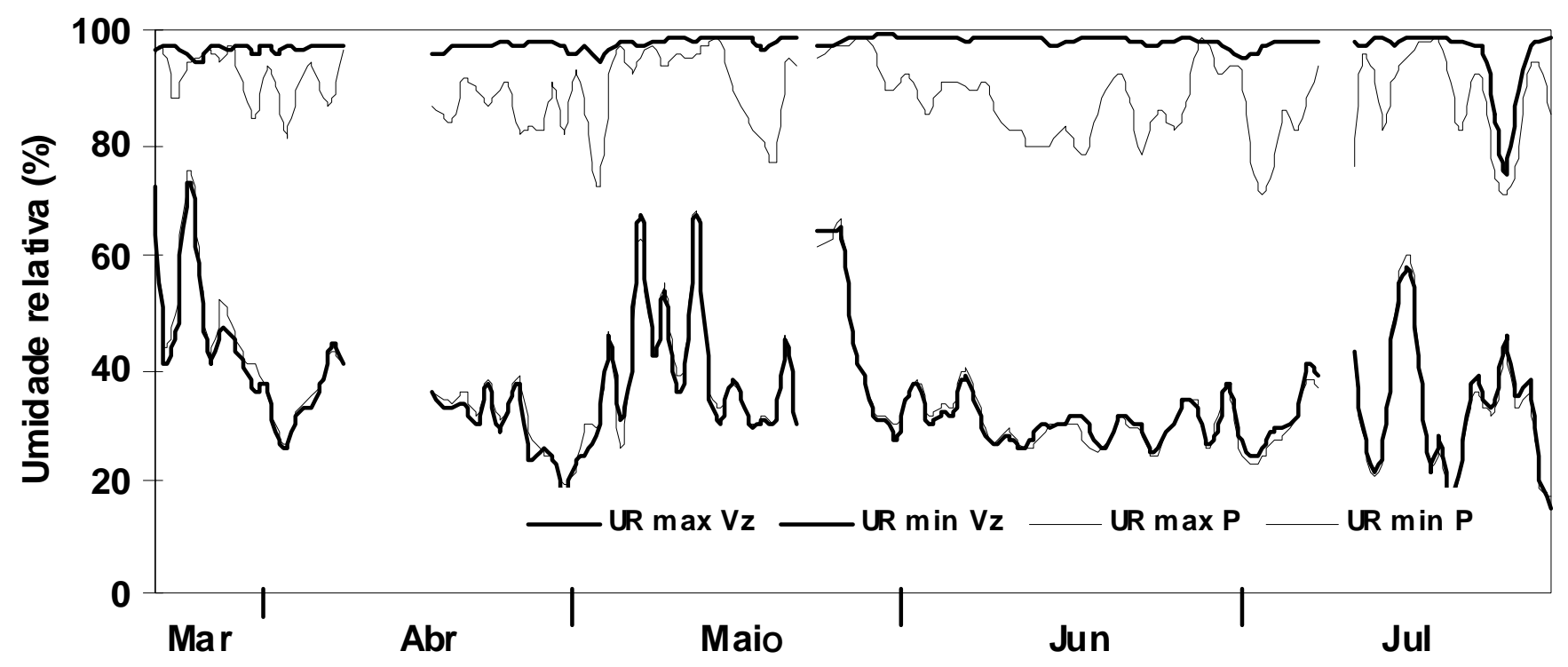

Figura 4. Umidade relativa máxima (URmax) e mínima (URmin) do ar para as condições de várzea (VZ) e de posto meteorológico (P), observadas durante o período de março/2002 a julho/2002, em Mococa (SP). 
Na várzea, os valores máximos da umidade do ar no período outono/inverno (Figura 4), ficaram sempre próximos a $100 \%$, enquanto no posto oscilou entre $70 \%$ e $98 \%$. Já os valores mínimos de UR foram semelhantes em ambos os ambientes avaliados.

Os maiores valores de UR máxima na várzea, obtidos tanto no período de primavera/verão quanto de outono/inverno, podem ter sido influenciados pelas características de topoclima, mais próprias ao acúmulo de ar frio e também por duas outras situa- ções, ou seja, o solo mais úmido que no posto, devido ao lençol freático mais superficial e à proximidade do rio que favorece maior umidade do ar.

\subsection{Evapotranspiração}

Os valores obtidos de evapotranspiração estimada para o posto meteorológico gramado e em condição de várzea são mostrados nas figuras 5 e 6 , para os períodos de primavera/verão e outono/inverno.

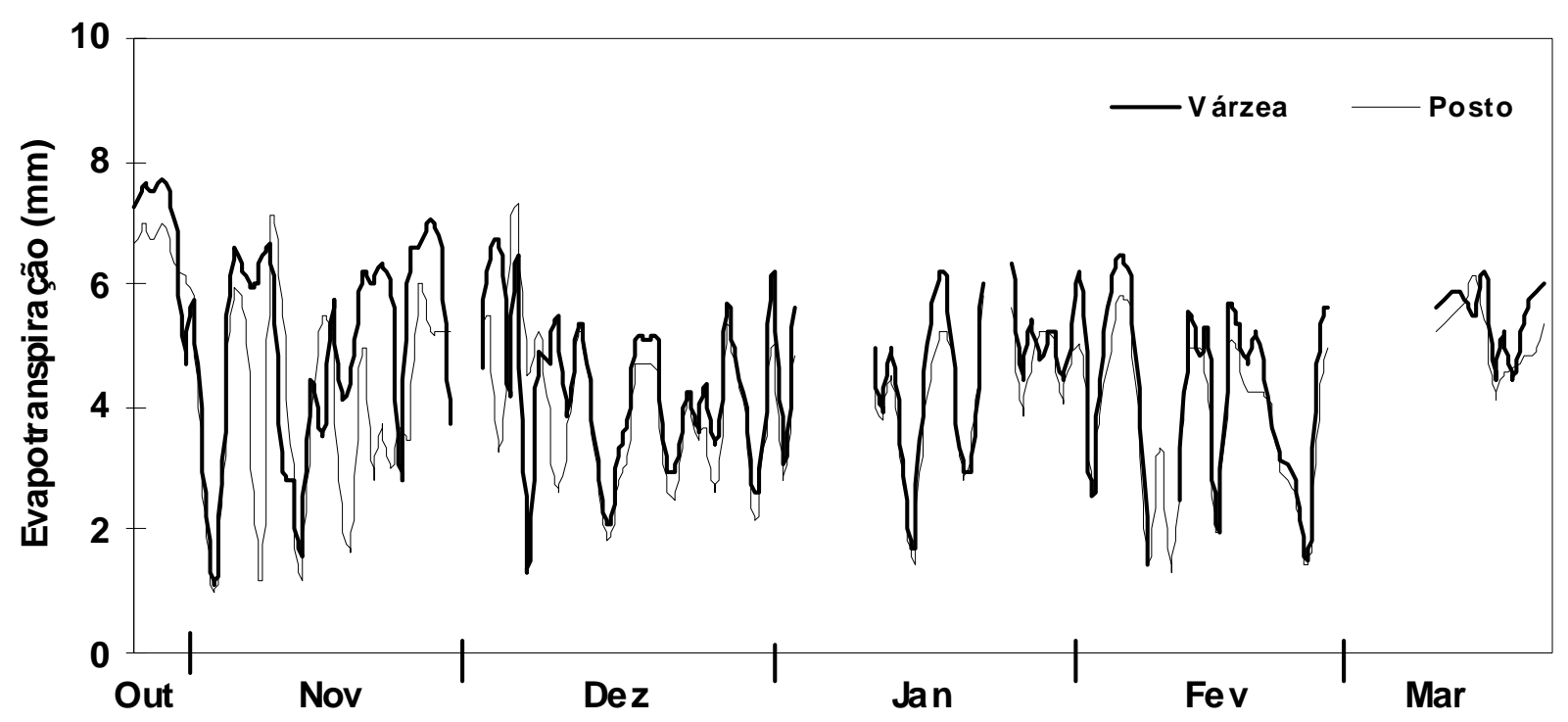

Figura 5. Evapotranspiração para as condições de várzea (Várzea) e de posto meteorológico (Posto), observadas durante o período de outubro/2001 a março/2002, em Mococa (SP).

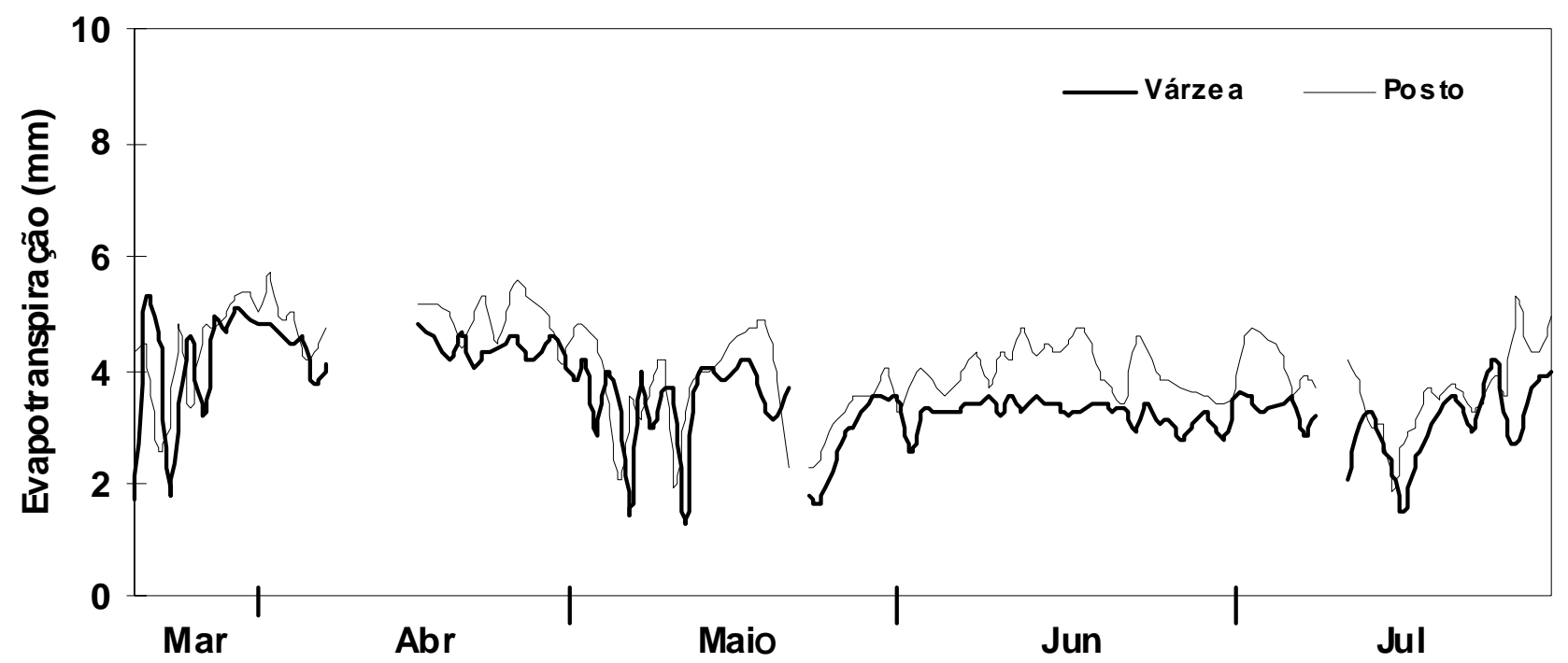

Figura 6. Evapotranspiração para as condições de várzea (Várzea) e de posto meteorológico (Posto) observadas durantes o período de março/2002 a julho/2002, em Mococa-SP. 
Observa-se que no período de primavera/verão os valores de evapotranspiração nas condições analisadas (posto e várzea) foram muito semelhantes (Figura 5). A evapotranspiração em ambos os ambientes variou entre extremos de 1,0 e $7,8 \mathrm{~mm}$ por dia com ocorrência de valores mais elevados no período outubro/novembro. Por outro lado, durante o outono/inverno as estimativas feitas para posto meteorológico foram superiores às da várzea. Esse fato provavelmente está relacionado às diferenças de umidade do ar e velocidade do vento entre os ambientes, tornando o parâmetro aerodinâmico da fórmula de Penman mais influente e com peso maior no caso das estimativas para o posto.

Nesse período (outono/inverno) fica evidenciado, principalmente no período de abril a junho, quando as condições de advecção, sendo mais acentuadas no ambiente de posto meteorológico, propiciam estimativas de evapotranspiração maiores no posto do que no ambiente de várzea.
A comparação entre a evapotranspiração em condições de várzea e a evapotranspiração no posto meteorológico, para os dois períodos de análise, indicou haver diferenças entre os ambientes, principalmente no período de outono/inverno.

Para analisar a causa dessas diferenças foram feitas correlações da evapotranspiração com a radiação solar e o saldo de radiação.

Os resultados obtidos de coeficiente de determinação das correlações entre a evapotranspiração e a radiação solar global e o saldo de radiação $(\mathrm{Rn})$, são apresentados na tabela 1.

Nota-se que no período primavera/verão, devido à alta correlação entre a evapotranspiração e a radiação solar e o saldo de radiação, o efeito advectivo, ou seja, do termo aerodinâmico da fórmula de Penman foi menor, com coeficiente de determinação $\left(R^{2}\right)$ de 0,86 para as condições de posto e 0,93 para as de várzea.

Tabela 1. Comparação dos coeficientes de determinação $\left(R^{2}\right)$ das relações entre evapotranspiração (ET) e radiação solar global $(\mathrm{Rg})$ e saldo de radiação $(\mathrm{Rn})$ para os diferentes ambientes e épocas do ano.

\begin{tabular}{lcc}
\hline Local & ET x Rg & ET x Rn \\
\hline Posto P/V & 0,86 & 0,86 \\
Várzea P/V & 0,97 & 0,93 \\
Posto O/I & 0,58 & 0,58 \\
Várzea O/I & 0,88 & 0,88 \\
\hline
\end{tabular}

$\mathrm{PV}=$ primavera/verão; $\mathrm{O} / \mathrm{I}=$ outono/inverno.

MATZENAUER et al (1999) correlacionaram a ET obtida em lisímetro com valores de radiação solar global incidente para a cultura de milho. Esses autores relataram haver alta relação entre ET e $\mathrm{Rg}$, do mesmo modo como encontrado neste trabalho.

Por outro lado, durante o período de outono inverno, nas condições de posto meteorológico, os coeficientes de determinação foram mais baixos $\left(R^{2}=\right.$ $0,58)$, demonstrando maior efeito do termo aerodinâmico nas estimativas da evapotranspiração que no ambiente de várzea, para a qual o coeficiente de determinação foi mais elevado $\left(R^{2}=0,88\right)$.

Esse fato ocorreu, provavelmente, porque as condições de umidade de solo da várzea fizeram com que o termo do balanço de energia da fórmula de Penman tivesse maior influência, quando comparado ao posto onde o solo estava mais seco.

\subsection{Resumo das comparações microclimáticas em ambiente de várzea e posto meteorológico}

Na tabela 2 são apresentados os valores da diferença média dos parâmetros analisados para as condições de posto meteorológico e várzea, para as épocas primavera/verão e outono/inverno e os resultados de significância da análise de dados pareados.

Durante o período de primavera-verão $(\mathrm{P} / \mathrm{V})$ os valores de temperatura máxima, umidade relativa máxima e amplitude térmica foram superiores no ambiente de várzea em relação ao de posto meteorológico. Entretanto, os valores de temperatura mínima, umidade relativa mínima, velocidade do vento e evapotranspiração foram inferiores na várzea quando comparados aos do posto.

A mesma tendência desses parâmetros analisados se manteve durante o período de outono-inverno(O/I). Pode-se notar, porém, pela Tabela 2, que as diferenças entre os valores de temperatura mínima e evapotranspiração da várzea e do posto foram intensificadas em relação ao período P/V. Fato não caracterizado para a umidade relativa mínima e velocidade do vento. 
Tabela 2. Resumo da comparação das observações microclimáticas entre ambiente de várzea e de posto meteorológico

\begin{tabular}{|c|c|c|c|c|}
\hline Variável & Época & DT & NS & $R R$ \\
\hline Temperatura Máxima $\left({ }^{\circ} \mathrm{C}\right)$ & $\mathrm{P} / \mathrm{V}$ & 0,9 & * & Várzea>Posto \\
\hline Temperatura Máxima $\left({ }^{\circ} \mathrm{C}\right)$ & $\mathrm{O} / \mathrm{I}$ & 0,1 & * & Várzea>Posto \\
\hline Temperatura Mínima $\left({ }^{\circ} \mathrm{C}\right)$ & $\mathrm{P} / \mathrm{V}$ & $-0,5$ & * & Várzea<Posto \\
\hline Temperatura Mínima $\left({ }^{\circ} \mathrm{C}\right)$ & $\mathrm{O} / \mathrm{I}$ & $-3,4$ & * & Várzea<Posto \\
\hline Amplitude Térmica $\left({ }^{\circ} \mathrm{C}\right)$ & $\mathrm{P} / \mathrm{V}$ & 1,4 & * & Várzea>Posto \\
\hline Amplitude Térmica $\left({ }^{\circ} \mathrm{C}\right)$ & $\mathrm{O} / \mathrm{I}$ & 3,5 & * & Várzea>Posto \\
\hline Umidade Relativa Máxima $\left({ }^{\circ} \mathrm{C}\right)$ & $\mathrm{P} / \mathrm{V}$ & 2,9 & * & Várzea<Posto \\
\hline Umidade Relativa Máxima $\left({ }^{\circ} \mathrm{C}\right)$ & $\mathrm{O} / \mathrm{I}$ & 9,0 & * & Várzea<Posto \\
\hline Umidade Relativa Mínima $\left({ }^{\circ} \mathrm{C}\right)$ & $\mathrm{P} / \mathrm{V}$ & $-2,1$ & * & Várzea $<$ Posto \\
\hline Umidade Relativa Mínima $\left({ }^{\circ} \mathrm{C}\right)$ & $\mathrm{O} / \mathrm{I}$ & 0,0 & ns & Várzea<Posto \\
\hline Velocidade do Vento $\left(\mathrm{m} \cdot \mathrm{s}^{-1}\right)$ & $\mathrm{O} / \mathrm{I}$ & $-0,8$ & * & Várzea<Posto \\
\hline Velocidade do Vento $\left(\mathrm{m} \cdot \mathrm{s}^{-1}\right)$ & $\mathrm{P} / \mathrm{V}$ & $-0,7$ & * & Várzea<Posto \\
\hline Evapotranspiração $\left(\mathrm{mm} \cdot \mathrm{dia}^{-1}\right)$ & $\mathrm{P} / \mathrm{V}$ & $-0,2$ & * & Várzea $<$ Posto \\
\hline Evapotranspiração $\left(\mathrm{mm} \cdot \mathrm{dia}^{-1}\right)$ & $\mathrm{O} / \mathrm{I}$ & $-1,6$ & * & Várzea<Posto \\
\hline
\end{tabular}

$\mathrm{P} / \mathrm{V}=$ primavera /verão; $\mathrm{O} / \mathrm{I}=$ outono/inverno; $\mathrm{DT}=$ Diferença média entre os tratamentos. NS=nível de significância pela análise de variância dos dados pareados $:^{*}=5 \%$; $n s=$ não significativo, $R R=$ resultado resumido.

As diferenças entre várzea e posto com relação à temperatura máxima no $\mathrm{O} / \mathrm{I}$ e à evapotranspiração na $\mathrm{P} / \mathrm{V}$, apesar de serem muito pequenas, foram significativas ao nível de 5\% pela análise de dados pareados. A comparação da umidade relativa mínima nos dois ambientes mostrou-se não significativa.

A comparação das diferenças entre os ambientes de várzea e de posto meteorológico (Tabela 2) permitiu verificar que a várzea, devido às suas características topográficas, influenciou nos parâmetros microclimáticos analisados, de maneira a se sobrepor aos efeitos macroclimáticos.

O ambiente de várzea influiu favorecendo a ocorrência de maiores diferenças das condições microclimáticas, fazendo com que as temperaturas e umidade relativa máximas fossem mais elevadas, e as mínimas, mais baixas, quando comparadas ao posto meteorológico. Conseqüentemente, a amplitude térmica no ambiente de várzea foi mais elevada que no posto meteorológico. Essa característica fica mais evidente no período de outono/inverno, com relação à temperatura mínima, quando a diferença entre os ambientes foi mais acentuada.

\section{CONCLUSÕES}

1. No período de primavera-verão o ambiente de várzea mostrou temperaturas máximas e amplitudes térmicas mais elevadas e temperaturas mínimas menores; umidade relativa máxima mais elevada e umidade relativa mínima e evapotranspiração mais baixas.

2. No período de outono inverno no ambiente de várzea foram observadas maiores diferenças de temperatura mínima, umidade relativa máxima, amplitude térmica e evapotranspiração em comparação ao de posto meteorológico, sendo mais acentuadas que no período de primavera-verão. Ainda, foi notado um efeito mais acentuado do fator aerodinâmico da fórmula de estimativa da evapotranspiração.

\section{REFERÊNCIAS}

ABTEW, W. Evapotranspiration measurements and modeling for three wetland systems in south Florida. Water Resources Bulletin, Herndon, v. 32, n.3, p.465-473, 1996.

ALLEN, R.G.; JEMEN, M.E.; WRIGHT, J.L.; BURMAN, R.D. Operational Estimates of reference evapotranspiration. Agronomy Journal, Madison, v. 81, p.650-662, 1989.

ALLEN, R.G.; PEREIRA, L.S.; RAES, D.; SMITH, M. Crop evapotranspiration: Guidelines for computing crop water requirements, Rome: FAO, 1998. 300 p. (Irrigation and Drainage Paper, 56)

BERLATO, M.A.; MOLION, L.C.B. Evaporação e evapotranspiração. Porto Alegre: IPAGRO, 1981. 96p. (Boletim Técnico) 
CAMARGO, A.P. Agrometeorologia. Espírito Santo do Pinhal: Faculdade de Agronomia e Zootecnia "Manoel Carlos Gonçalves", 1972. 166p. (mimeografado).

GEIGER, R. The climate near the ground. $2^{\text {nd }}$ ed. Cambridge, Massachusets, USA: Harvard University Printing Office, 1950. 482p.

HUBBARD, K.G.; SIVAKUMAR, M.V.K. (Eds.). Automated Weather Stations for Applications in Agriculture and Water Resources Management: Current Use and Future Perspectives. In: INTERNATIONAL WORKSHOP HELD IN LINCOLN, 2000, Nebraska, USA. Proceedings... Lincoln, Nebraska: High Plains Climate Center and Geneva, Switzerland: World Meteorological Organization. 2001. 248p.

MAO, L.M.; BERGMAN, M.J.; TAI, C.C. Evapotranspiration measurement and estimation of three wetland environments in the Upper St. Johns River Basin, Florida. Journal of the American Water Resources Association, Middleburg, v.38, n.5, p.1271-1285, 2002.

MATZENAUER, R.; MALUF, J.R.T.; BUENO, A.C. Relações entre a evapotranspiração máxima do feijoeiro (Phaseolus vulgaris L.) com a evapotranspiração de referência e com a radiação solar global. Revista Brasileira de Agrometeorologia, Santa Maria, v.7, n.2, p.173-178, 1999.

PENMAN, H.L. Natural evaporation from open water, bare soil and grass. Royal Society of London Proceedings, London, v.193, p.120-146. 1948.
PEREIRA, A.R.; SENTELHAS, P.C.; FOLEGATTI, M.V.; VILLA NOVA, N.A.; MAGGIOTTO, S.R.; PEREIRA, F.A.C. Substantiation of the daily FAO-56 reference evapotranspiration with data from automatic and conventional weather stations. Revista Brasileira de Agrometeorologia, Santa Maria, v.10, n.2, p.251-257, 2002.

PEREIRA, A.R.; VILLA NOVA, N.A.; SEDIYAMA, G.C. Evapotranspiração. Piracicaba: FEALQ, 1997. 183p.

PEREIRA, A.R.; ANGELOCCI, L.R.; SENTELHAS, P.C. Agrometeorologia: fundamentos e aplicações práticas. Porto Alegre: Guaíba Agropecuária, 2002,478p.

PEREIRA, A.R.; SENTELHAS, P.C.; VILLA NOVA, N.A. Estimativa do balanço de energia radiante em função de elementos climáticos. Revista Brasileira de Agrometeorologia, Santa Maria, v.6, n.2, p.2001-206, 1998.

SOKAL, R.R.; ROHLF, F.J. Biometry. San Francisco; W.H. Freeman, 1969. 776p.

WESSEL, D.; ROUSE, W. Modeling evaporation from wetland Tundra. Boundary Layer Meteorology, Boston, v.68, n. 1-2, p.109-130, 1994.

YOSHINO, M.M. Climate in a small area: An Introduction to local meteorology. Tokyo: University of Tokyo Press, 1975. 549p. 